\title{
Human Striatal Dopaminergic and Regional Serotonergic Synaptic Degeneration with Lewy Body Disease and Inheritance of APOE \&4
}

\author{
Nadia Postupna, ${ }^{*}$ Caitlin S. Latimer, ${ }^{*}$ Eric B. Larson, ${ }^{\dagger}$ Emily Sherfield, ${ }^{*}$ Julie Paladin, ${ }^{*}$ Carol A. Shively, \\ Matthew J. Jorgensen, ${ }^{\ddagger}$ Rachel N. Andrews, ${ }^{\ddagger}$ Jay R. Kaplan, ${ }^{\ddagger}$ Paul K. Crane, ${ }^{\S}$ Kathleen S. Montine, ${ }^{*}$ Suzanne Craft, \\ C. Dirk Keene, ${ }^{*}$ and Thomas J. Montine ${ }^{*}$
}

From the Departments of Pathology* and Medicine, ${ }^{\S}$ University of Washington, Seattle, Washington; the Group Health Research Institute, ${ }^{\dagger}$ Seattle, Washington; and the Department of Pathology, ${ }^{\ddagger}$ Section on Comparative Medicine, and the Department of Internal Medicine, ${ }^{\top}$ Wake Forest School of Medicine, Winston-Salem, North Carolina

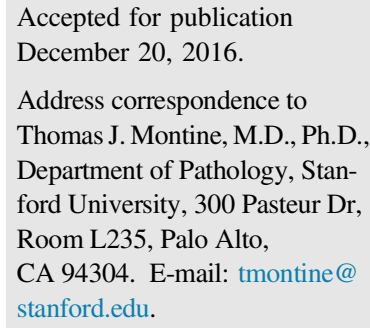

\begin{abstract}
Cognitive impairment in older individuals is a complex trait that in population-based studies most commonly derives from an individually varying mixture of Alzheimer disease, Lewy body disease, and vascular brain injury. We investigated the molecular composition of synaptic particles from three sources: consecutive rapid autopsy brains from the Adult Changes in Thought Study, a population-based cohort; four aged nonhuman primate brains optimally processed for molecular investigation; and targeted replacement transgenic mice homozygous for $A P O E \& 4$. Our major goal was to characterize the molecular composition of human synaptic particles in regions of striatum and prefrontal cortex. We performed flow cytometry to measure six markers of synaptic subtypes, as well as amyloid $\beta 42$ and paired helical filament tau. Our results showed selective degeneration of dopaminergic terminals throughout the striatum in individuals with Lewy body disease, and serotonergic degeneration in human ventromedial caudate nucleus from individuals with an $A P O E \varepsilon 4$ allele. Similar results were seen in mouse caudate nucleus homozygous for $A P O E \& 4$ via targeted replacement. Together, extension of these clinical, pathologic, and genetic associations from tissue to the synaptic compartment of cerebral cortex and striatum strongly supports our approach for accurately observing the molecular composition of human synapses by flow cytometry. (Am J Pathol 2017, 187: 884-895; http://dx.doi.org/10.1016/j.ajpath.2016.12.010)
\end{abstract}

Cognitive impairment in older individuals is a complex trait that in population-based studies most commonly derives from an individually varying mixture of Alzheimer disease (AD), Lewy body disease (LBD), and vascular brain injury (VBI). LBD has two clinical categories: Parkinson disease (PD), which is commonly accompanied by significant cognitive impairment or dementia (referred to as PDD), and dementia with Lewy bodies (DLB), where dementia appears before the onset of motor symptoms. For AD, the primary regions of focus have been medial temporal lobe structures and regions of cerebral cortex, although it is now recognized that amyloid $\beta(\mathrm{A} \beta)$ accumulation in striatum typically marks the transition from preclinical disease to $\mathrm{AD}$ dementia., Cognitive impairment in PD, PDD, and DLB involves mesostriatal or mesocortical dopaminergic degeneration, and thereby directly or indirectly affects prefrontal cortex function, either alone or in combination with AD. ${ }^{3,4}$ Thus, AD and LBD share involvement of striatum and prefrontal cortex.

The pathogenesis of both $\mathrm{AD}$ and LBD is proposed to initiate through regional synaptic injury and degeneration. Many groups have quantified loss of synaptic proteins from homogenates of involved human $(\mathrm{Hu})$ brain regions in $\mathrm{AD}$ and $\mathrm{LBD}^{5-7}$ but this approach excludes the synaptic

\footnotetext{
Supported by NIH grants P30AG049638, P40OD010965, P50AG05136, P50NS062684, P50AG047366, and U01AG006781, and Nancy and Buster Alvord Endowment.

Disclosures: E.B.L. received royalties from UpToDate.

Current address of K.S.M. and T.J.M., Department of Pathology, Stanford University, Palo Alto, CA.
} 
Table 1 Criteria for Clinicopathologic Groups

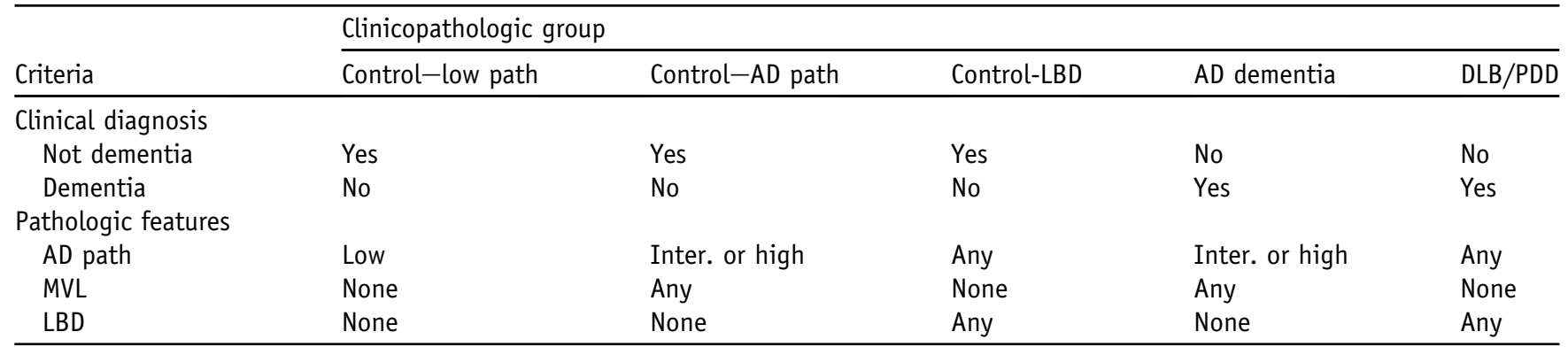

AD, Alzheimer disease; DLB, dementia with Lewy bodies; Inter., intermediate; LBD, Lewy body disease; MVL, microvascular lesion; path, pathological change; PDD, Parkinson disease dementia.

terminal and is confounded by quantification of proteins that are ultimately destined for, but have not yet reached, the synapse. Other studies have relied on ultrastructural approaches or Golgi staining, which allow direct observation of synapses; however, such approaches are laborious and thereby limited to relatively few synapses, and are not readily adapted to molecular investigation. ${ }^{8,9}$ Recently, we have followed a method pioneered by Gylys and colleagues $^{10-14}$ that uses flow cytometry to probe the molecular composition of thousands of particles within the size gate for synaptosomes from Hu brain regions. Although Gylys and colleagues ${ }^{10-14}$ focused on regions of cerebral cortex and hippocampus from $\mathrm{Hu}$ postmortem tissue and mouse $(\mathrm{Mu})$ models of $\mathrm{AD}$, we focused on the striatum and prefrontal cortex in Hu postmortem tissue and Mu models of dopaminergic degeneration. ${ }^{15}$ So far, all work from both groups has used brain autopsies obtained from research cohorts, and hence likely presents a skewed view of synaptic injury that occurs as we age and become vulnerable to latent and then clinically overt AD and LBD.

Herein, we investigated the molecular composition of synaptic particles from three sources: 40 consecutive rapid autopsy brains from a population-based cohort, four aged nonhuman primate (NHP) brains optimally processed for molecular investigation because of their close genomic, proteomic, and neuroanatomic homology to $\mathrm{Hu}$, and transgenic Mu brain to test cause-and-effect relationships. ${ }^{16,17}$ For each, we used flow cytometry focused on six markers of synaptic subtypes and two pathogenic proteins [amyloid $\beta 42$ $\left(\mathrm{A} \beta_{42}\right)$ and paired helical filament tau (PHF-tau)] in cerebral cortex and striatum. Our results showed selective degeneration of dopaminergic terminals throughout the striatum in individuals with $\mathrm{LBD}$ and serotonergic degeneration in $\mathrm{Hu}$ ventromedial caudate (VMC) nucleus from individuals with an $A P O E \varepsilon 4$ allele, as well as in Mu caudate nucleus homozygous for $A P O E \varepsilon 4$ via targeted replacement. ${ }^{18}$

Table 2 Immunolabeling Strategy

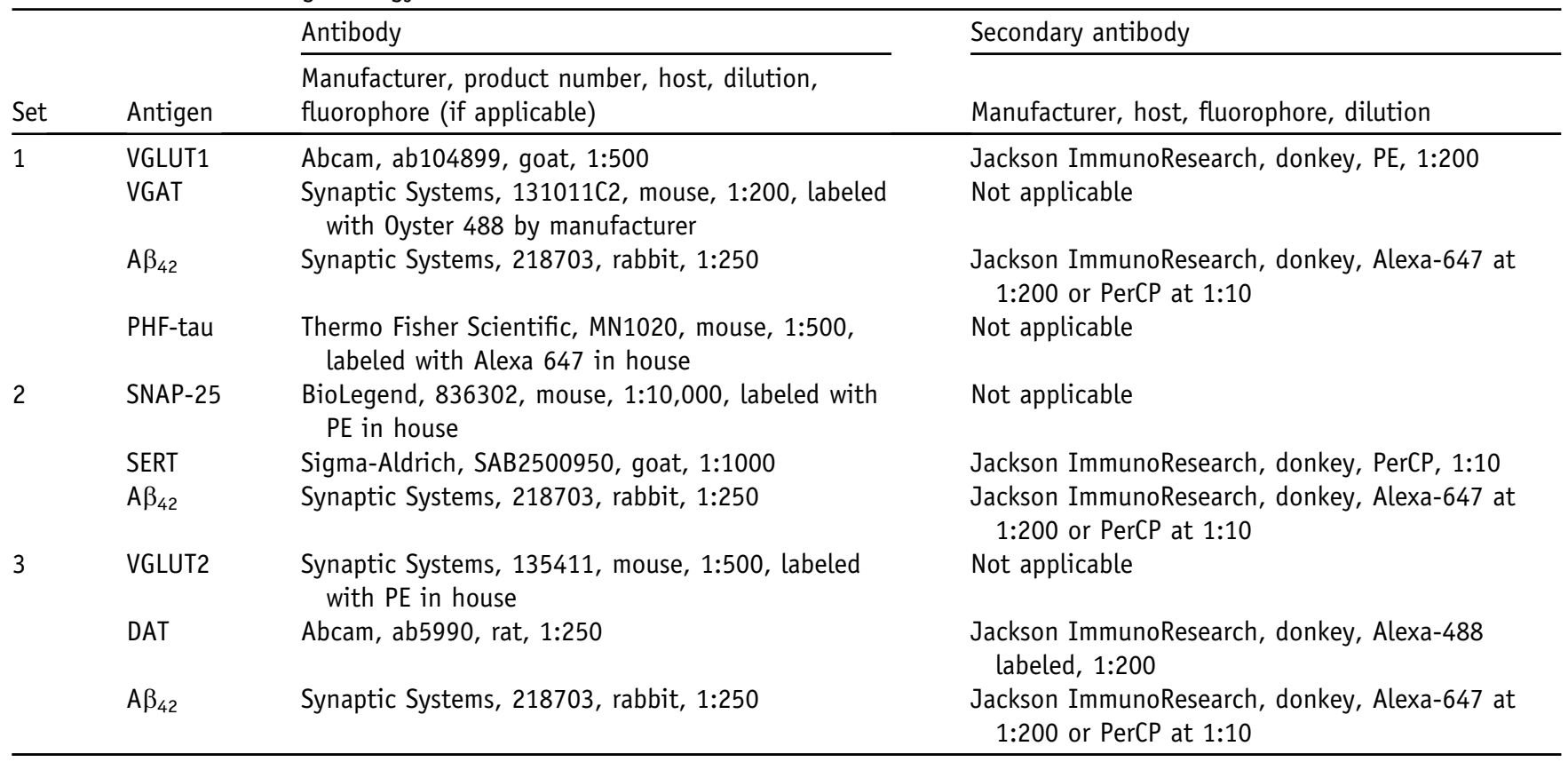

A $\beta$, amyloid $\beta$; DAT, dopamine transporter; PE, R-phycoerythrin; PerCP, peridinin chlorophyll protein; PHF, paired helical filament; SNAP-25, synaptosomalassociated protein 25; SERT, serotonin transporter; VGAT, vesicular GABA transporter; VGLUT, vesicular glutamate transporter. 


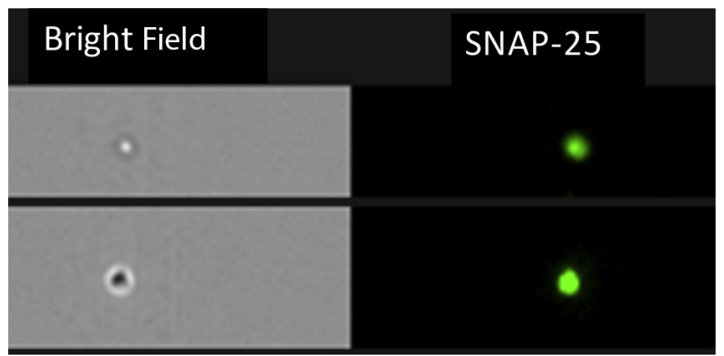

Figure 1 Two Hu synaptosome particles passing through a flow chamber. Image was taken by ImageStream flow cytometer. The bright field microscope image shows one particle slightly out of focus; the SNAP-25 image was simultaneously recorded using a fluorescent camera. Particles were immunolabeled with anti-SNAP-25 antibody conjugated to a green fluorophore (Alexa 488).

\section{Materials and Methods}

\section{Brain Autopsy}

This study was approved by the University of Washington (Seattle, WA) Institutional Review Board. Tissue samples $(\leq 1 \mathrm{~g})$ were collected from consecutive autopsies of participants in the Adult Changes in Thought Study, a population-based study of brain aging and incident dementia in volunteers 65 years of age or older. ${ }^{19}$ Exclusion criteria were as follows: postmortem interval of $>8$ hours, neuropathologic evaluation that revealed territorial or lacunar infarct(s) or hemorrhage(s), or evidence of neurodegenerative disease other than AD or LBD. These 40 consecutive participants comprised 17 men and 23 women, with a median age at death of 89.5 years. The Adult Changes in Thought Study evaluates participants biennially until diagnosis of dementia; the median interval between last clinical evaluation and death for individuals without dementia was 464 days. Brain autopsy regions sampled for synaptosome preparation were the middle frontal gyrus (MFG; Brodmann area 9), the head of the caudate nucleus (separated into ventromedial caudate or VMC, and dorsolateral caudate), and the putamen.

In some analyses, results were stratified by clinical and pathological features. Clinical diagnoses of dementia were made as previously described ${ }^{20}$ by a consensus panel of experts using the Diagnostic and Statistical Manual of Mental Disorders-IV $V^{21}$ and the National Institute of
Neurological and Communicative Disorders and Stroke/ Alzheimer's Disease and Related Disorders Association ${ }^{22}$ standard criteria. Similarly, neuropathologic features were evaluated exactly by consensus guidelines. ${ }^{23,24}$ Criteria for clinic-pathologic grouping are presented in Table 1.

\section{Experimental Animals}

All $\mathrm{Mu}$ procedures were conducted in accordance with the guidelines of the Institutional Animal Care and Use Committee at University of Washington. Mice homozygous for targeted replacement (TR) of the $\mathrm{Mu}$ apoE gene with exon 1 of $\mathrm{Hu}$ $A P O E \varepsilon 3$ (APOE3) or APOE \&4 (APOE4) backcrossed onto a C57BL/6 genetic background were a gift from Dr. Nobuyo Maeda (The University of North Carolina, Chapel Hill, NC) ${ }^{18}$ and used in our previous studies. ${ }^{25-31}$ Homozygous TR APOE3 (8 males and 13 females) and homozygous TR APOE4 (7 males and 13 females) mice were sacrificed at 6 months of age, their brains rapidly removed, and cerebral cortex and striatum collected for synaptosome preparation.

All NHP procedures were performed at Wake Forest University (Winston-Salem, NC) with approval from the Institutional Animal Care and Use Committee, according to recommendations in the Guide for Care and Use of Laboratory Animals (Institute for Laboratory Animal Research) and in compliance with the US Department of Agriculture Animal Welfare Act and Animal Welfare Regulations (Animal Welfare Act as Amended; Animal Welfare Regulations). NHP tissue was obtained from four female African green monkeys (Chlorocebus aethiops sabaeus) at the time of necropsy for a study of aging. Median age was 22.6 years. After the animals were sacrificed, brains were immediately removed, and tissue samples from the mid-frontal cortex and striatum (caudate and putamen combined because of small size) collected for synaptosome preparation. One of the neuropathologists from University of Washington (C.D.K.) was present to ensure that tissue for NHP was prepared exactly the same as for Hu brain.

\section{Preparation of the Crude Synaptosome Fraction}

The crude synaptosome fraction (P2) preparation protocol was adapted from Gylys et al, ${ }^{14}$ and described previously by

Table 3 Distribution of Cases by Clinicopathological Evaluation

\begin{tabular}{|c|c|c|c|c|c|c|}
\hline Variable & Control-low path & Control-AD path & Control-LBD & AD dementia & DLB/PDD & Total \\
\hline Cases, $n$ & 7 & 10 & 2 & 16 & 5 & 40 \\
\hline $\begin{array}{l}\text { Last CASI score } \\
\quad(\text { means } \pm \text { SD) }\end{array}$ & $94 \pm 3$ & $90 \pm 5$ & 95 and 93 & Not applicable & Not applicable & Not applicable \\
\hline$A D$ path & $\begin{array}{l}7 \text { Low, } 0 \text { inter., } \\
0 \text { high }\end{array}$ & $\begin{array}{l}0 \text { Low, } 4 \text { inter., } \\
6 \text { high }\end{array}$ & $\begin{array}{l}1 \text { Low, } 1 \text { inter., } \\
0 \text { high }\end{array}$ & $\begin{array}{l}0 \text { Low, } 1 \text { inter., } \\
15 \text { high }\end{array}$ & $\begin{array}{l}0 \text { Low, } 2 \text { inter., } \\
3 \text { high }\end{array}$ & $\begin{array}{l}8 \text { Low, } 8 \text { inter., } \\
24 \text { high }\end{array}$ \\
\hline$M V L \geq 3$ & 0 & 1 & 0 & 4 & 0 & 5 \\
\hline
\end{tabular}

${ }^{*} A P O E$ genotype was not available for two participants.

AD, Alzheimer disease; CASI, Cognitive Assessment Screening Instrument; DLB, dementia with Lewy bodies; inter., intermediate; LBD, Lewy body disease; MVL, microvascular lesion; path, pathological change; PDD, Parkinson disease dementia. 
us. ${ }^{15}$ In brief, samples were minced, slowly frozen in $0.32 \mathrm{~mol} / \mathrm{L}$ sucrose with $10 \%$ dimethyl sulfoxide, and stored at $-80^{\circ} \mathrm{C}$. To obtain the crude synaptosome fraction, the

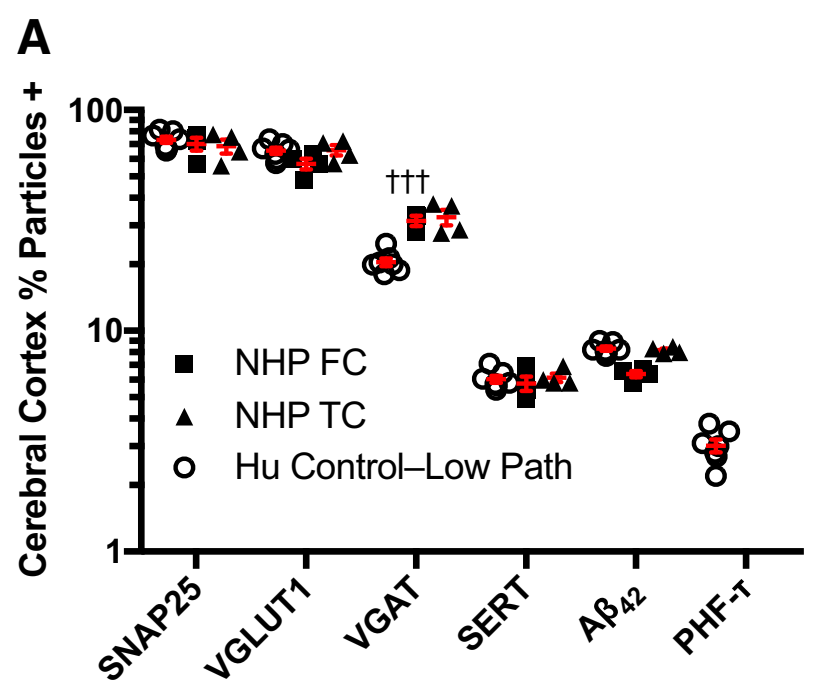

B

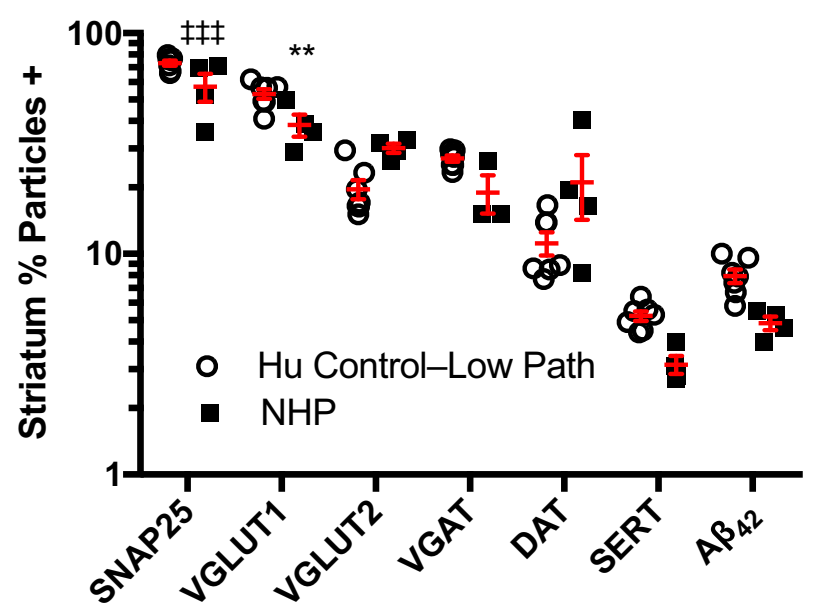

Figure 2 Comparison of human $(\mathrm{Hu})$ and nonhuman primate (NHP) synaptosomes. Samples are from brain autopsies of individuals without dementia at last clinical evaluation, and whose neuropathologic evaluation showed no or low Alzheimer disease (AD) neuropathologic change, no Lewy body disease (LBD), and no vascular brain injury (VBI); we labeled this group Control-Low Path (Table 3). NHP necropsies were from healthy older animals whose neuropathologic evaluation showed no $A D$ neuropathologic change, no LBD, and no VBI. Data are percentage particles + for synaptic marker, and are presented on a log scale as scatter plots with means and SEM drawn in red. A: Cerebral cortical samples are from Hu middle frontal gyrus (MFG) and from NHP frontal cortex (FC) or temporal cortex (TC). The percentage particles +VGAT is significantly lower for Hu MGF than for NHP FC or TC. B: NHP striatum was prepared as a single homogenate because of its small size; comparable results were obtained by averaging data from three regions of $\mathrm{Hu}$ striatum that were prepared separately. Hu striatum has significantly greater percentage particles +SNAP-25 and percentage particles +VGLUT1 than NHP. $n=7$ brain autopsies of individuals (A and $\mathbf{B}) ; n=4 \mathrm{NHP}$ necropsies (A and $\mathbf{B})$. ${ }^{* *} P<0.01$ for percentage particles +VGLUT1 for Hu striatum versus NHP; ${ }^{\dagger \dagger \dagger} P<0.001$ for percentage particles +VGAT for Hu MGF vs NHP FC or TC; $\ddagger \ddagger \rrbracket<0.001$ for percentage particles +SNAP-25 for Hu striatum versus NHP. minced tissue was thawed and homogenized in $0.32 \mathrm{~mol} / \mathrm{L}$ sucrose in $10 \mathrm{mmol} / \mathrm{L}$ Tris buffer with proteinase and phosphatase inhibitors using a glass/Teflon homogenizer. The homogenate was centrifuged at $1000 \times g$ at $4^{\circ} \mathrm{C}$ for 10 minutes, then the supernatant was removed and centrifuged again at $12,000 \times g$ at $4^{\circ} \mathrm{C}$ for 20 minutes. Resulting pellets were resuspended in sucrose/Tris solution and stored at $-80^{\circ} \mathrm{C}$

\section{Immunolabeling of the Synaptosome Fraction}

The immunolabeling protocol has been described previously. ${ }^{15}$ For Hu and NHP samples, we used three combinations of primary antibodies. Set 1 used antibodies against vesicular glutamate transporter 1 (VGLUT-1), vesicular GABA transporter (VGAT), and $A \beta_{42}$ (and PHF-tau in the $\mathrm{Hu}$ MFG samples). Set 2 used antibodies against synaptosome-associated protein 25 (SNAP-25), serotonin transporter (SERT), and $A \beta_{42}$. Set 3 used antibodies against VGLUT-2, dopamine transporter (DAT), and $\mathrm{A} \beta_{42}$ (Table 2). Primary antibodies were purchased from Abcam (Cambridge, UK) (DAT and VGLUT1); Biolegend (San Diego, CA) (SNAP-25); Sigma-Aldrich (St. Louis, MO) (SERT); Synaptic Systems (Goettingen, Germany) (A $\beta_{42}$, VGAT, and VGLUT2); and ThermoFisher Scientific (Waltham, MA) (PHF-tau). Donkey secondary antibodies were purchased from Jackson ImmunoResearch (West Grove, PA).

\section{Flow Cytometry}

All data presented are for synaptosome suspensions analyzed using an Apogee A50 flow cytometer (Apogee Flow Systems, Hertfordshire, UK) equipped with 15-mW 488-nm (blue) and 633-nm (red) lasers. Silica microspheres (Spherotech Inc., Lake Forest, IL) of varying size $(0.5$ and $1.2 \mu \mathrm{m})$ were used as size standards, and size gate was set as previously described. ${ }^{15}$ At least 10,000 gated events were collected per sample. For Figure 1 only, we imaged $\mathrm{Hu}$ synaptic particles, in this instance labeled for SNAP-25, passing though the flow chamber, with an ImageStream X Mark II imaging flow cytometer (Amnis, WA) equipped with 488-, 405-, and 647-nm lasers.

Each sample was incubated with both the primary antibody to the protein of interest and the respective isotype control antibody, used as negative control. The positive gate was set on the sample incubated with the isotype control and adjusted to include $1 \%( \pm 0.1 \%)$ of the total size-gated particle population.

\section{Statistical Analysis}

Data were analyzed using GraphPad Prism (San Diego, CA) version 7 to perform one- or two-way analysis of variance, followed by post tests corrected for multiple comparisons. Correlation was determined with Pearson's correlation coefficient. $\alpha$ was set at $P<0.05$. 


\section{Results}

Interpretation of $\mathrm{Hu}$ synaptosome data requires careful consideration of the unique circumstances that surround collection of autopsy tissue. Unlike samples prepared immediately from euthanized animals, the molecular composition of $\mathrm{Hu}$ synaptic preparations may change in response to agonal events or degradation within our short (by autopsy standards) 8-hour postmortem interval, thereby systemically altering results. For comparison, we made identical synaptosome preparations from aged NHP scheduled for euthanasia, eliminating agonal illness and postmortem interval. We performed the same neuropathologic workup on the NHP samples as for $\mathrm{Hu}$ samples; NHP showed diffuse $A \beta$ plaques in the posterior temporal cortex only, similar to previous reports, ${ }^{32}$ but no neurofibrillary degeneration, LBD, or VBI (data not shown).

To make the most direct comparison, we minimized the effect of disease in $\mathrm{Hu}$ samples by including only the Control-Low Path group: those individuals who were diagnosed as not dementia at last clinical evaluation and whose neuropathologic evaluation showed no or low levels of AD neuropathologic change, no LBD, and no or low VBI, as measured by number of microvascular lesions in standardized sections ${ }^{23,24}$ (Table 3). NHP and Hu Control-Low Path (clinically control with low AD pathology) groups were well matched for relative age expressed as fraction of maximum age: assuming a maximum lifespan of 30 years for this species of NHP and of 120 years for humans, average fraction $( \pm \mathrm{SD})$ of maximum lifespan was $0.74 \pm 0.06$ for NHP and $0.74 \pm 0.07$ for Hu Control-Low Path group. Results comparing the two synaptic preparations are presented in Figure 2. Data are the percentage particles immunoreactive among the total number of gated events, and are presented on a log scale. The percentage of particles positive $(\%$ particles + ) for the six synaptic markers varied widely, with SNAP-25 being the most prevalent synaptic maker and SERT the least prevalent synaptic marker in both cerebral cortex and striatum. Significant quantitative differences were observed in cerebral cortex, where percentage particles + VGAT was similar in NHP regions but less in $\mathrm{Hu}$ MFG $(P<0.001)$, and in striatum where percentage particles +SNAP-25 $(P<0.001)$ and percentage particles +VGLUT1 $(P<0.01)$ were greater in Hu than NHP preparations. The distribution of data for each synaptic marker in each species was limited, except for NHP striatal DAT. In this instance, the highest percentage particle +DAT was from the youngest NHP (fraction of maximal age, 0.66), perhaps suggesting marked age-related decline in relatively older NHP and Hu Control-Low Path. In addition to six synaptic markers, we also probed for two disease-related proteins in synaptic particles. $A \beta_{42}$ was detected at comparable levels in MFG and striatal synaptic particles from both $\mathrm{Hu}$ and NHP preparations; PHF-tau was undetectable in synaptic preparations from Hu or NHP MFG. In summary, these data demonstrate that there was not significant molecular degeneration of synaptosome $\mathrm{Hu}$ preparations with no/low levels of disease compared to relative agematched NHP preparations, despite Hu samples potentially influenced by agonal state and postmortem interval, and the NHP samples prepared optimally for research.

We next pursued correlation of synaptic data with consensus neuropathologic assessments of AD and LBD in all $40 \mathrm{Hu}$ samples (Figure 3). Our goal was to determine whether the well-established relationships between consensus neuropathologic scores and regional tissue concentrations of $\mathrm{A} \beta$ peptides, PHF-tau, and DAT also were reflected in the synaptic compartment. Increasing National
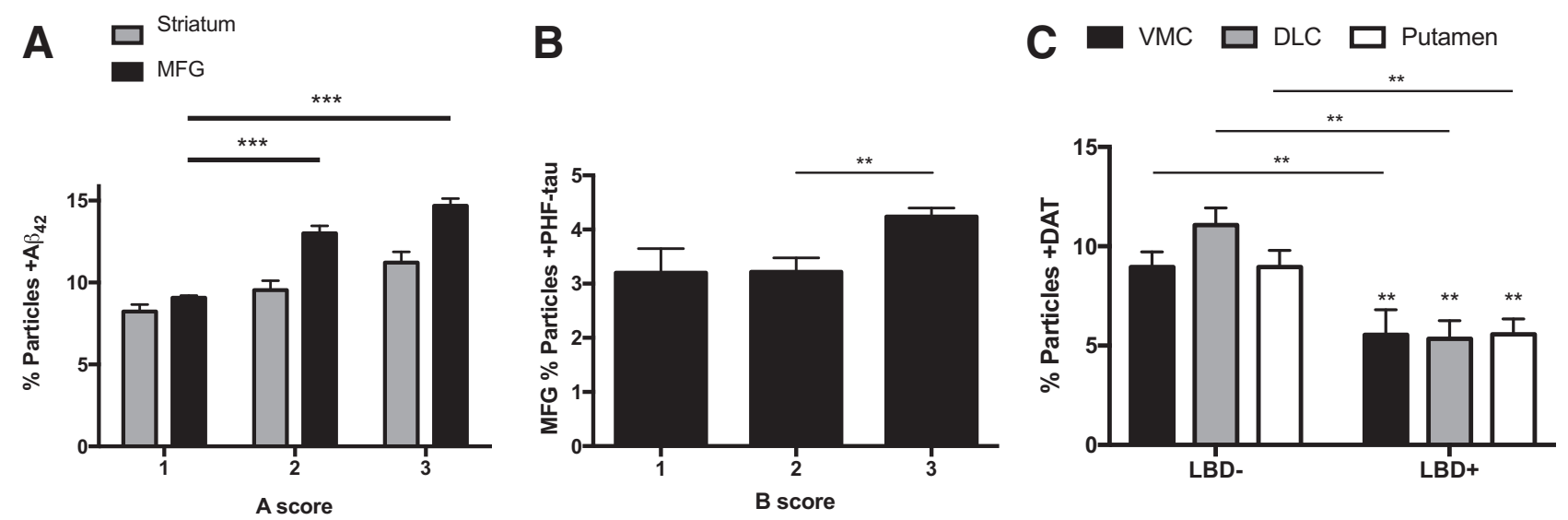

Figure 3 Neuropathologic correlates with synaptic particle molecular markers from 40 brain autopsies. A: Values for striatum are the average of ventromedial caudate (VMC), dorsolateral caudate (DLC), and putamen. Percentage particles $+A \beta_{42}$ in striatum and middle frontal gyrus (MFG) stratified by National Institute on Aging - Alzheimer's Association (NIA-AA) A score for A $\beta_{42}$ deposition. Two-way analysis of variance shows $P<0.0001$ for $A$ score and brain region, and $P<0.05$ for interaction. Corrected multiple paired comparisons for regions show significance for A score 2 or 3 versus A score 1. B: MFG percentage particles +PHF-tau stratified by NIA-AA B score for neurofibrillary degeneration. One-way analysis of variance shows $P<0.01$; corrected multiple paired comparisons show significance for B score 3 versus B score 1 (and also versus B score 2). C: Percentage particles +DAT in three regions of Hu striatum stratified by + Lewy body disease $(+\mathrm{LBD})$ or $-\mathrm{LBD}$. Two-way analysis of variance is significant only for $\mathrm{LBD}(P<0.0001)$; corrected multiple paired comparisons for region show significance for $\mathrm{LBD}+$ versus $-\mathrm{LBD}$ in each region. ${ }^{* *} P<0.01,{ }^{* *} P<0.001$. 


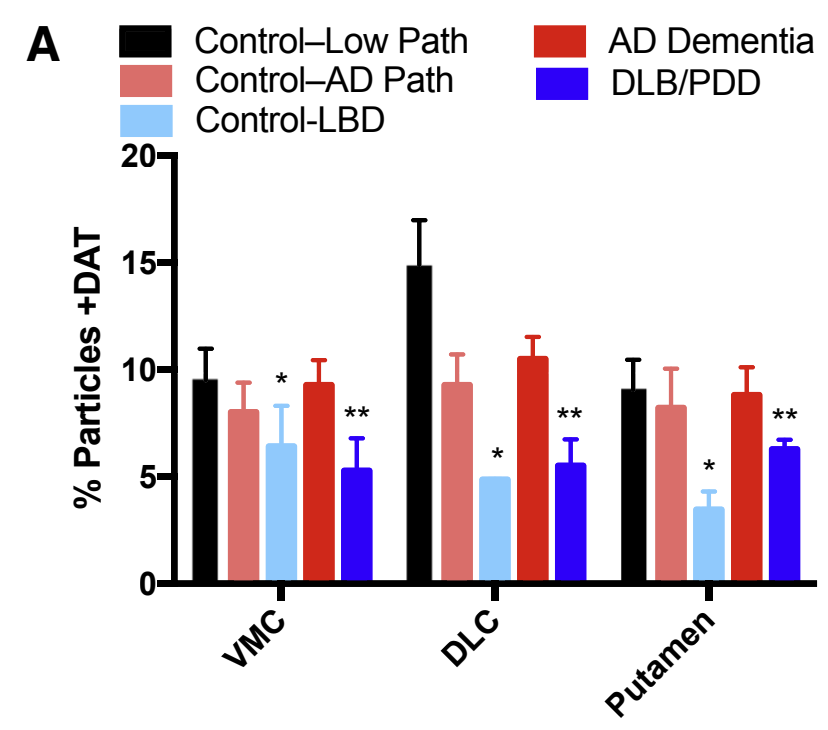

B
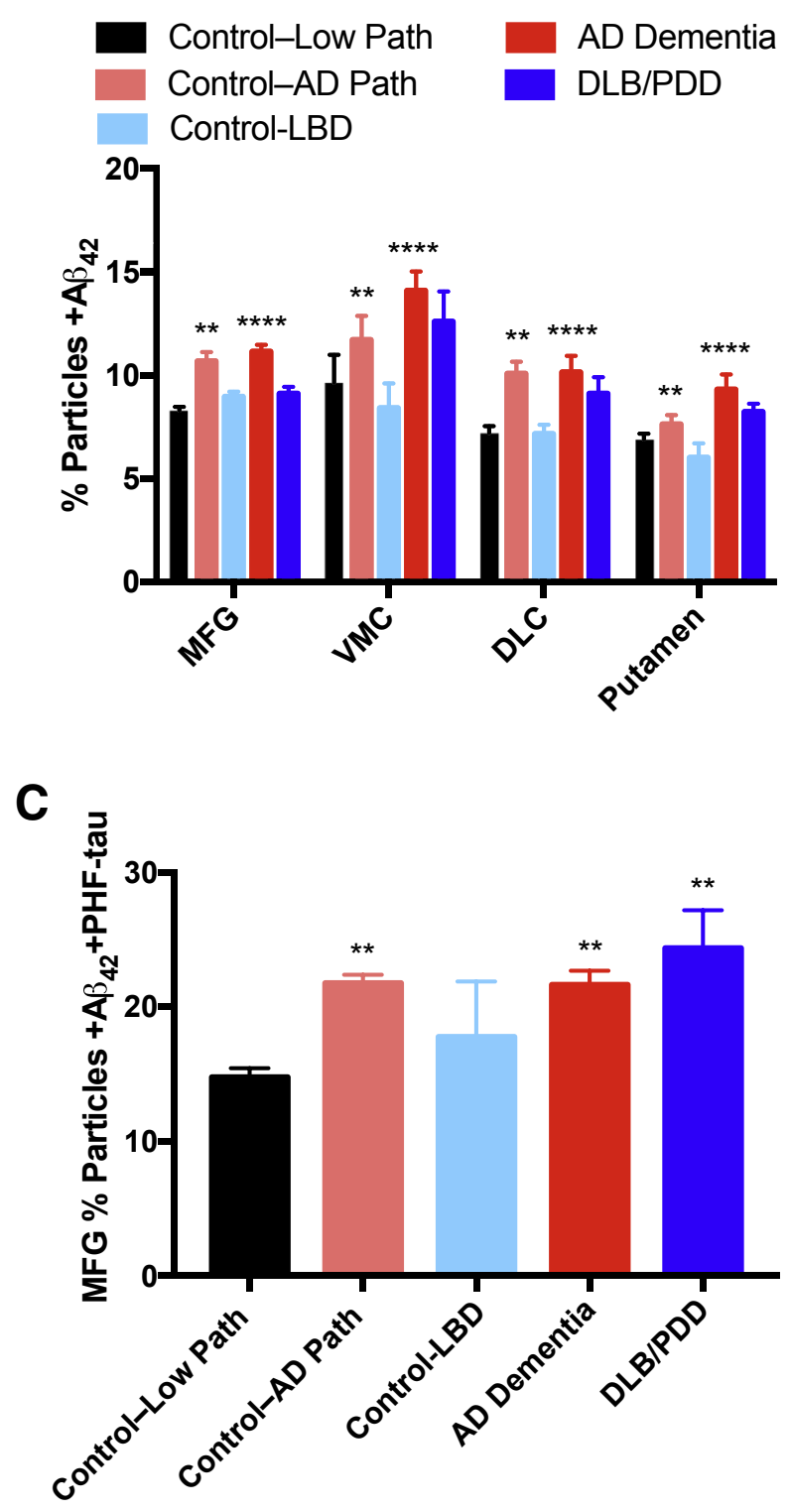

Institute on Aging - Alzheimer's Association (NIA-AA) A score (a consensus neuropathologic index for senile plaque accumulation) was associated with progressively increasing synaptic $A \beta_{42}$ in MFG and striatum synaptic particles, with levels in MFG significantly exceeding striatum at A scores of $2(P<0.001)$ and $3(P<0.001)$, similar to others' data for $A \beta$ peptides in synaptosomes prepared from the parietal cortex. ${ }^{10}$ Many groups have demonstrated that an NIA-AA B score (extent of neurofibrillary degeneration) of 3 is associated with appearance of cerebral cortical neurofibrillary degeneration and increased tissue concentration of PHF-tau in isocortical regions, including MFG. We observed that MFG percentage particles +PHF-tau was significantly increased with an NIA-AA B score of 3 compared with B scores of 1 or $2(P<0.01)$, again in close agreement with parietal cortex synaptosome pathological tau. ${ }^{10}$ Finally, LBD was closely associated with degeneration in mesostriatal dopaminergic system; cases with LBD had significant reduction in percentage particles + DAT by region in two-way analysis of variance $(P<0.0001)$; corrected multiple paired comparisons were significant for each region of striatum $(P<0.01)$. We analyzed separately the five cases with clinically meaningful burden of microvascular lesions, ${ }^{23,24}$ but found no significant difference between this group and Control-Low Path for any of the synaptic proteins assayed. Overall, these results demonstrate that correlations made repeatedly between consensus neuropathologic scores and regional tissue levels of $A \beta_{42}$, PHF-tau, and DAT extend to the synaptic compartment, validate recent results from comparable investigation of the parietal cortex for $\mathrm{A} \beta$ peptides and pathological tau, ${ }^{10}$ and broadly support our approach to investigating $\mathrm{Hu}$ synapses.

We next stratified our $\mathrm{Hu}$ data into clinicopathologic groups (Table 3) to incorporate functional state proximate to death, as well as the burden of specific diseases evaluated by pathological scores. We focused first on synaptic DAT; twoway analysis of variance showed that the percentage particles + DAT varied significantly by clinicopathologic group $(P<0.001)$, but not by region or interaction. Corrected multiple paired comparisons showed that percentage particles + DAT were significantly reduced for DLB/PDD $(P<0.01)$ and for Control-LBD groups $(P<0.05)$ compared to Control-Low Path (Figure 4A). Although the number of individuals in the Control-LBD group is small, these data suggest that LBD is malignant to dopaminergic presynaptic elements even in the absence of a clinical diagnosis of DLB or PDD. Figure 4B shows percentage

\footnotetext{
Figure 4 Clinicopathologic correlates with synaptic particle molecular markers from $40 \mathrm{Hu}$ brain autopsies. A: The percentage particles +DAT varies significantly by clinicopathologic group $(P<0.001)$ but not by region or interaction. Corrected multiple paired comparisons show significance for DLB/PDD and for Control-LBD groups compared to Control-Low Path. B: The percentage particles $+A \beta_{42}$ increase in $A D$ dementia and Control-AD Path. C: The percentage particles $+A \beta_{42}$ also + PHF-tau increase in Control-AD Path, AD dementia, and DLB/PDD. ${ }^{*} P<0.05$, ${ }^{* *} P<0.01$, and ${ }^{* * * *} P<0.0001$ versus Control-Low Path.
} 
particles $+\mathrm{A} \beta_{42}$ in four different regions for the five clinicopathologic groups $(P<0.0001$ for region and $P<0.0001$ for group, no significant interaction). Corrected multiple comparisons showed that percentage particles $+\mathrm{A} \beta_{42}$ were increased in $\mathrm{AD}$ dementia $(P<0.0001)$ and in Control-AD Path (not dementia with intermediate or high AD pathology; $P<0.01)$. MFG percentage particles + PHF-tau trended toward higher levels in AD dementia, DLB, and Control-AD Path groups but was not significant $(P=0.08)$. However, a significant association $(P<0.01)$ was observed for percentage particles $+\mathrm{A} \beta_{42} /+$ PHF-tau (Figure $4 \mathrm{C}$ ); corrected multiple comparisons, percentage particles $+\mathrm{A} \beta_{42} /+\mathrm{PHF}-$ tau had $P<0.01$ for Control-Low Path versus Control-AD Path, versus AD dementia, and versus DLB/PDD. Our results for $+\mathrm{DAT},+\mathrm{A} \beta_{42}$, or + PHF-tau synaptic particles are broadly consistent with numerous clinicopathologic studies of brain tissue and further validate our approach. Our results with $+\mathrm{A} \beta_{42}$ and + PHF-tau particles in MFG suggest that synaptic colocalization with these two proteins may be a closer correlate of clinical expression of disease than + PHFtau alone.

The observation that LBD was associated with a decrease in percentage particles +DAT demonstrated that our approach can detect selective neurodegenerative changes in the synaptic compartment. Interestingly, when extended to senile (A score) or neuritic ( $\mathrm{C}$ score) plaque burden or extent of neurofibrillary degeneration (B score), we did not observe significant correlation with any of the synaptic markers in MFG or regions of striatum. We explored these relationships further by correlating synaptic results for $A \beta_{42}$ or PHF-tau with synaptic markers (Figure 5). Of the four synaptic markers assayed in MFG (SNAP-25, VGLUT1, VGAT, and SERT), percentage particles $+\mathrm{A} \beta_{42}$ and percentage particles + PHF-tau positively correlated with each other $(P<0.0001)$ but not with any of the synaptic markers (Figure 5A), consistent with the lack of correlation between consensus neuropathologic scores and synaptic markers. In striatum, percentage particles $+\mathrm{A} \beta_{42}$ strongly correlated positively with percentage particles + VGAT $(P<0.0001)$ or + SERT $(P<0.0001)$ in each of the three subregions and when combined into a single analysis (Figure 5B). Striatal percentage particles $+\mathrm{A} \beta_{42}$ also correlated positively with VGLUT1 and DAT in VMC and putamen, but not in dorsolateral caudate; specifically, percentage particles $+\mathrm{A} \beta_{42}$ correlated with percentage particles +VGLUT1 in VMC $(P<0.01$, Pearson $r=0.46)$ and putamen $(P<0.01$, Pearson $r=0.48)$, and with percentage particles + DAT in VMC $(P<0.01$, Pearson $r=0.41)$ and putamen $(P<0.001$, Pearson $r=0.51)$. In summary, although LBD was associated with selective reduction in percentage particles $+\mathrm{DAT}$, consensus scores for AD neuropathologic change, synaptic percentage particles $+\mathrm{A} \beta_{42}$, or percentage particles +PHF-tau were not associated with selective reduction of any synaptic marker in cerebral cortex or striatum. Rather than negatively, striatal percentage particles $+\mathrm{A} \beta_{42}$ positively correlated with percentage particles +VGLUT1, +VGAT, +SERT, and +DAT in the same subregions.

We pursued further the distribution of $A \beta_{42}$ in different types of synapses by determining the colabeling of particles with $A \beta_{42}$ and synaptic markers (Figure 6). For these analyses, we returned to pathological groups defined by consensus pathological scores because adding clinical diagnosis to stratify further yielded similar results (data not shown). Two-way analysis of variance had significant differences (pathological group and region) for percentage particles colabeled with $A \beta_{42}$ and the following synaptic markers: VGLUT1 $(P<0.0001$ and $P<0.0001)$, VGAT $(P<0.0001$ and $P<0.0001)$, and VGLUT2 $(P<0.0001$ and $P<0.0001)$. More important, percentage + SERT, and + DAT particles did not vary significantly by pathological group or region. Corrected multiple comparisons for
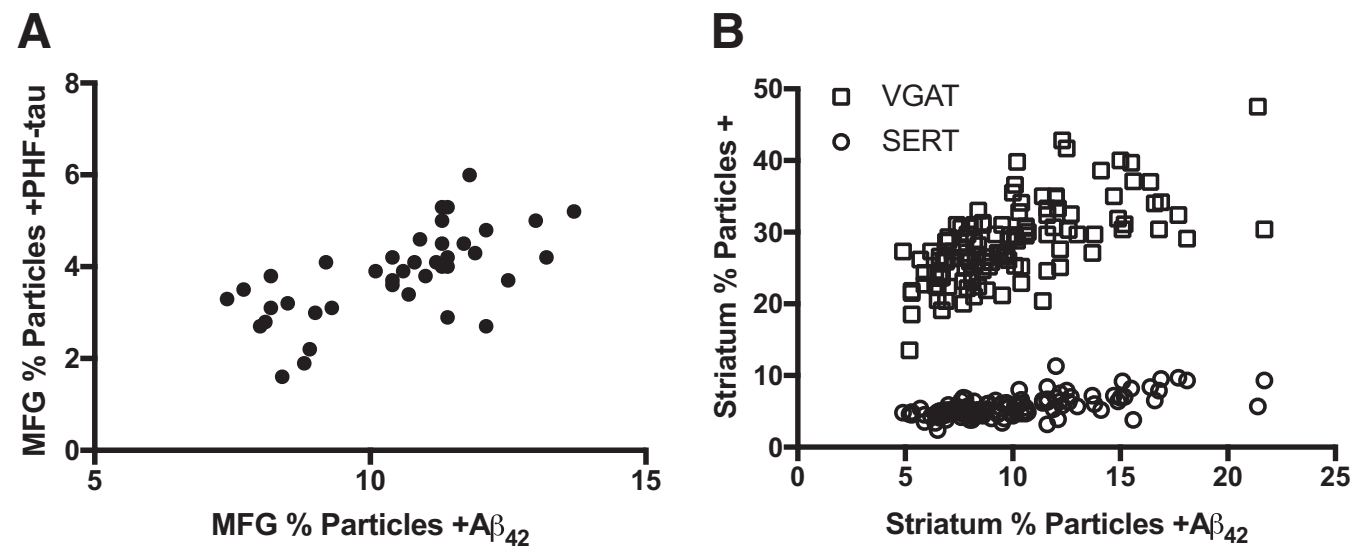

Figure 5 Regional correlations between percentage particles + for synaptic markers (SNAP-25, VGLUT1, VGAT, and SERT) and percentage particles $+A \beta_{42}$ or +PHF-tau from $40 \mathrm{Hu}$ brain autopsies. A: In middle frontal gyrus (MFG), percentage particles $+\mathrm{A} \beta_{42}$ or + PHF-tau do not correlate with any of the synaptic markers but positively correlate with each other $(P<0.0001$, Pearson $r=0.65)$. B: In striatum, percentage particles $+\mathrm{A} \beta_{42}$ correlate positively with percentage particles +VGAT $(P<0.0001$, Pearson $r=0.65)$ or + SERT $(P<0.0001$, Pearson $r=0.65)$ in each of the three subregions and when combined into a single analysis, but not with any of the other synaptic markers. 
A
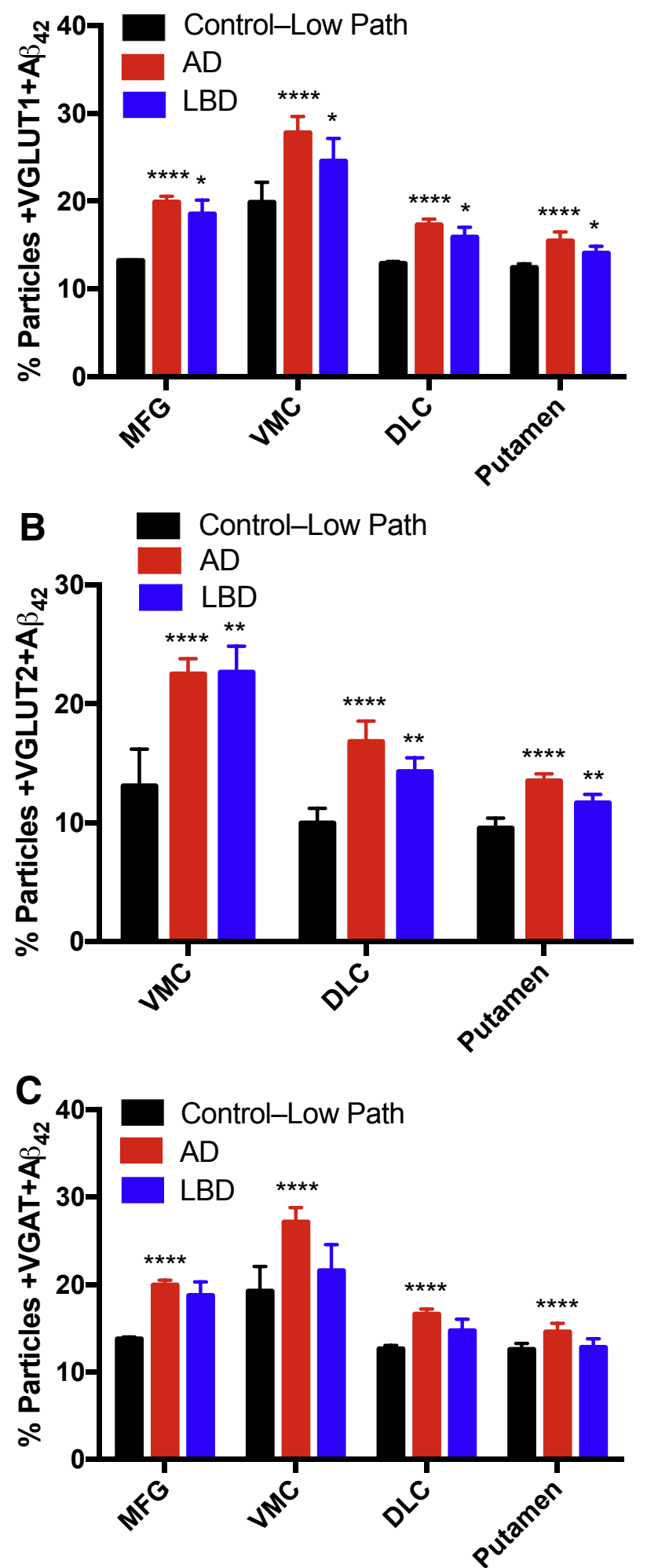

Figure 6 Regional accumulation of percentage particles colabeled with synaptic marker and $A \beta_{42}$ in pathological groups from $40 \mathrm{Hu}$ brain autopsies. A: +VGLUT1/ $+A \beta_{42}$ for Control-Low Path versus AD show significance and versus LBD show significance. B: + VGLUT2/ $+A \beta_{42}$ for Control-Low Path versus $A D$ show significance and versus $L B D$ had significance. $C:+V G A T /+A \beta_{42}$ for Control-Low Path versus AD show significance and versus $L B D$ is not significant. ${ }^{*} P<0.05,{ }^{* *} P<0.01$, and ${ }^{* * *} P<0.0001$ versus Control-Low Path.
VGLUT1, VGAT, and VGLUT2 each had $P<0.0001$ for Control-Low Path versus AD; in addition, Control-Low Path versus LBD for VGLUT1 had $P<0.05$, VGLUT2 had $P<0.01$, and VGAT was nonsignificant. These data indicate that synaptic accumulation of $\mathrm{A} \beta_{42}$ in $\mathrm{AD}$ occurred in excitatory and inhibitory synapses in both the MFG and striatum. $A \beta_{42}$ also accumulated in LBD in MFG and striatum but less consistently than with $\mathrm{AD}$ and significantly only in excitatory synapses.

Given the association of $A P O E \varepsilon 4$ with risk for $\mathrm{AD}$ and cognitive impairment in $\mathrm{PD}$, we investigated the relationship between inheritance of one or two APOE $\varepsilon 4$ alleles and regional synaptic proteins levels in Hu samples (Figure 7). Inheritance of an $A P O E \varepsilon 4$ was associated with increased synaptic $\mathrm{A} \beta_{42}$ by both region $(P<0.0001)$ and genotype $(P<0.0001)$, with percentage particles $+\mathrm{A} \beta_{42}$ greater with $A P O E \quad \varepsilon 4$ in all regions assayed. MFG percentage particles +PHF-tau was not significantly associated with $A P O E \varepsilon 4$. SERT was the only one of the six synaptic markers that significantly varied by $A P O E$ genotype $(P<0.01)$; percentage particles + SERT also varied by region $(P<0.05)$ with a significant interaction term $(P<0.01)$. Corrected multiple paired comparisons showed that the percentage particles +SERT in individuals with APOE $\varepsilon 4$ was significantly lower only in the VMC $(P<0.001)$.

We tested the unexpected correlation of reduced striatal percentage particles +SERT in Mu homozygous for TR of exon 1 of the $\mathrm{Mu} a p o E$ gene with $\mathrm{Hu}$ exon 1 from either APOE $\varepsilon 3$ or $A P O E \varepsilon 4$ to yield TR APOE3/3 or TR APOE4/4. ${ }^{18}$ Using exactly the same approach as for Hu and NHP brain regions, cerebral cortex, and striatum percentage particles + SERT varied significantly by region $(P<0.0001)$ and by TR APOE genotype $(P<0.01)$, and there was a significant interaction term $(P<0.05)$. Corrected multiple paired comparisons for percentage particles + SERT had $P<0.001$ in striatum but were not significantly different in cerebral cortex (Figure 8A). In contrast, percentage particles + for VGLUT1, VGLUT2, VGAT, or DAT varied significantly by region $(P<0.0001)$ but were not different between TR APOE3/3 and TR APOE 4/4; Figure 8B shows the example of percentage particles +DAT in TR APOE mice. These experimental data from TR APOE mice confirm experimentally our observation in $\mathrm{Hu}$ tissue that percentage particles + SERT are selectively reduced in striatum with expression of $A P O E \varepsilon 4$.

\section{Discussion}

The major goal of our study was to characterize the molecular composition of $\mathrm{Hu}$ synaptic particles in regions of striatum and prefrontal cortex, from older individuals who volunteered to participate in a population-based study. We organized our study around consecutive Adult Changes in Thought Study brain autopsies that met our inclusion criteria to minimize potential selection bias and maximize 
A

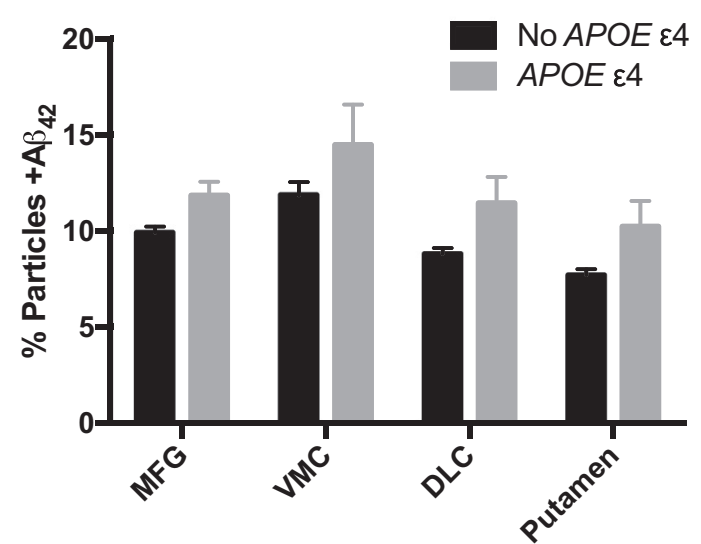

B

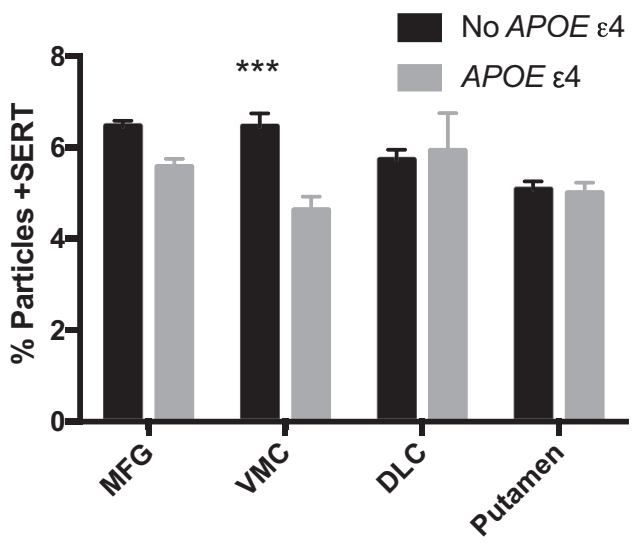

Figure 7 Regional correlation of synaptic molecules with inheritance of APOE $\varepsilon 4$ allele from $40 \mathrm{Hu}$ brain autopsies. A: Two-way analysis of variance shows $P<0.0001$ for presence of $A P O E \& 4$ and for region; however, no specific region is significantly different between $A P O E$ genotypes when corrected for multiple paired comparisons. B: Percentage particles +SERT in individuals with an APOE $\varepsilon 4$ is significantly lower only in the VMC. ${ }^{* *} P<0.001$ versus $A P O E \varepsilon 4$.

the representation of the two neurodegenerative diseases that most commonly cause cognitive impairment and dementia in older individuals: AD and LBD. Indeed, the prevalence of these two diseases in our group of 40 cases matches closely their prevalence in the overall Adult Changes in Thought Study autopsy cohort and other population-based studies on brain aging and dementia that have autopsy end point. ${ }^{33}$ Our major findings were two types of selective synaptic degeneration in $\mathrm{Hu}$ striatum: dopaminergic degeneration with LBD and regional serotonergic degeneration with inheritance of APOE $\varepsilon 4$.

For the experiments presented herein, and in our previous work, we used the crude synaptosome fraction, or P2. ${ }^{15}$ There are several reasons for this: i) this approach aligns with the extensive characterization performed by Gylys and colleagues, ${ }^{10-14}$ ii) similar to others, in our experience further enrichment of synaptosomes by gradient centrifugation does not result in higher percentage particles + SNAP-25, and iii) the yield from gradient-purified preparations is significantly reduced. In a previous publication, we presented transmission electron micrographs of our synaptosome preparation from $\mathrm{Hu}$ brain that demonstrates abundant synaptic particles. ${ }^{15}$ Herein, we extended the characterization of the $\mathrm{Hu}$ particles undergoing flow cytometry by using ImageStream to visualize single SNAP25-labeled particles.

It is important to stress that our intent was to investigate synaptic molecular composition, and that the particles harvested from $\mathrm{Hu}$ brain are no longer functional, unlike synaptosomes harvested by identical protocols from experimental animals. We sought first to determine whether the circumstances that surround death of a person, including varying conditions of agonal state and postmortem intervals of up to 8 hours, might cause systematic changes in synaptic molecular composition. To address this important issue as definitively as possible, we used identically prepared synaptosomes from NHP that were matched well for absence of pathological evidence of disease and fraction of maximum age, and were euthanized for another study, thus eliminating agonal state and post-mortem interval. Our results showed broadly similar outcomes for $\mathrm{Hu}$ and NHP preparations for the six synaptic markers and $A \beta_{42}$ with significantly lower percentage particles +VGAT in $\mathrm{Hu}$ cerebral cortex, and significantly higher +SNAP-25 and +VGLUT1 particles in Hu striatum, compared to NHP. In addition to these few quantitative differences, +PHF-tau particles were qualitatively different and detected only in $\mathrm{Hu}$ preparations, and then only in cerebral cortex. Although there are some species differences, these results from NHP and $\mathrm{Hu}$ brain tissue largely unaffected by disease show no pattern of molecular decay in Hu brain, and underline the fidelity with which our Hu preparations reflect the molecular composition of synaptic particles.

We observed anticipated correlations between consensus neuropathologic scores or clinicopathologic groupings and synaptic $A \beta_{42}$ or PHF-tau. Despite using different tissue resources, technology, and antibodies, our results for $A \beta_{42}$ and PHF-tau in MFG validate recent findings for $A \beta$ peptides and pathological tau in cerebral cortex by others, ${ }^{10}$ and show that these pathological proteins accumulate in the synaptic compartment in parallel with their well-known pattern of accumulation in whole tissue in AD. Our cohort also included individuals without dementia but with neuropathologic features of disease; this is an important group whose results showed that these pathological proteins accumulate in synapses during the preclinical stages of disease. Finally, we report for the first time that synaptic $\mathrm{A} \beta_{42}$, and not simply tissue level, is increased with inheritance of $A P O E$ \&4 (Figure 7). Together, extension of these clinical, pathologic, and genetic associations from tissue to the synaptic compartment of cerebral cortex and striatum strongly supports our approach for accurately observing the molecular composition of $\mathrm{Hu}$ synapses by flow cytometry. 


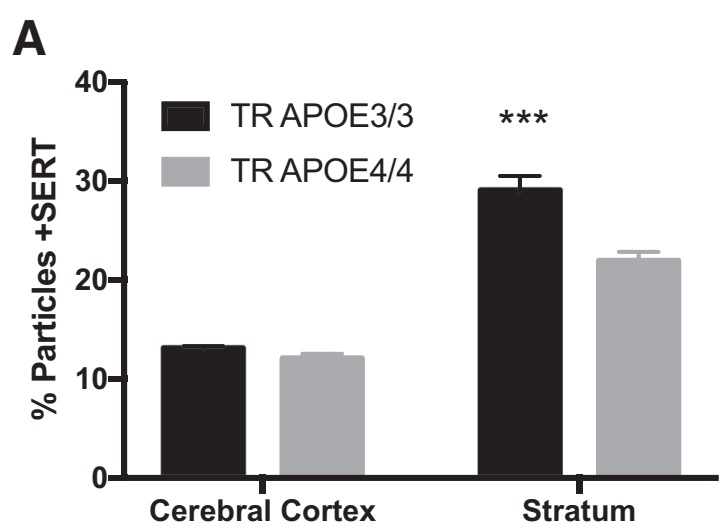

B

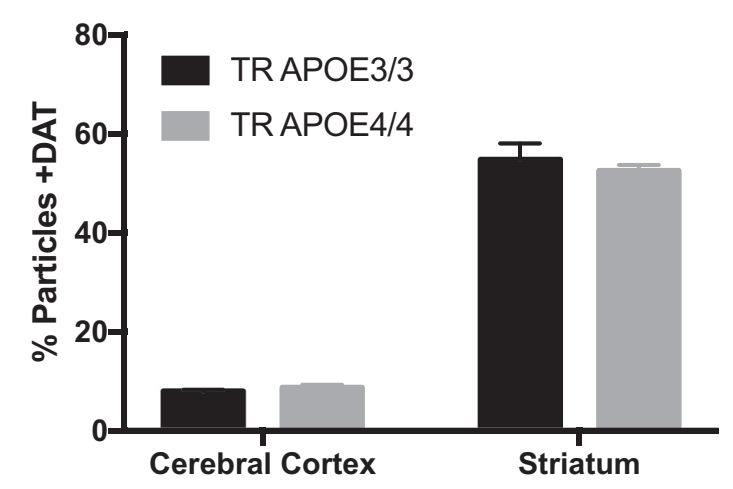

Figure 8 Cerebral cortical or striatal synaptic particles in adult targetedreplacement (TR) mice homozygous for APOE3/3 or AP0E4/4. A: Cerebral cortex and striatum percentage particles + SERT varies significantly by region $(P<0.0001)$ and by TR APOE genotype $(P<0.01)$. Corrected multiple paired comparisons for percentage particles + SERT show significance for striatum but are not significant in cerebral cortex. B: Percentage particles +DAT vary significantly by region $(P<0.0001)$ but there is no difference between TR APOE3/3 and TR APOE 4/4. ${ }^{* * * P}<0.001$ versus $4 / 4$.

Our group has uniquely focused on flow cytometry of $\mathrm{Hu}$ synaptic preparations from striatum. We observed two types of synaptic degeneration in $\mathrm{Hu}$ striatum. First was the selective reduction in striatal percerntage particles + DAT in individuals with pathological evidence of LBD. This was an expected finding that replicated our previous work, and that we validated in toxin-exposed mice. ${ }^{15}$ Interestingly, we also observed selective reduction in striatal percentage particles + SERT in individuals with an APOE $\varepsilon 4$ allele. We validated this unexpected finding experimentally in TR APOE mice. The central presynaptic serotonergic system shows limited degeneration with advancing age, but is reported to degenerate at least in some individuals with $\mathrm{AD}$ or PD. ${ }^{34}$ Because inheritance of $A P O E \varepsilon 4$ is a risk factor for both $\mathrm{AD}$ and $\mathrm{PDD},{ }^{35-37}$ our data suggest that earlier observations may have been confounded by disproportionate segregation of $A P O E$ \&4 carriers into the $\mathrm{AD}$ or PD groups. We found no other report of experiments investigating the central serotonergic system in TR APOE mice, or molecular imaging data of the $\mathrm{Hu}$ central serotonergic system stratified by $A P O E$ genotypes. However, recent work has associated $A P O E \varepsilon 4$ with risk of depression in cognitively normal older adults. ${ }^{38}$ Our novel association of regional loss of serotonergic synapses with $A P O E \varepsilon 4$ will require further validation, likely through molecular neuroimaging.

We observed no evidence of selective synaptic degeneration in MFG from AD or LBD. Indeed, others who have focused on the parietal cortex also did not observe significant differences between $\mathrm{AD}$ and controls for synaptic particles marked by VGLUT1 or VGLUT2 (the only two presynaptic markers used) and particles labeled with postsynaptic markers. ${ }^{13}$ We extended these findings to include three other synaptic subtypes in MFG particles: SNAP-25, VGAT, and SERT. In combination, this lack of synaptic degeneration in cerebral cortex of $\mathrm{AD}$ is somewhat perplexing given that the MFG and parietal cortex both atrophy in $\mathrm{AD}$, and that our approach demonstrated degeneration of synaptic particles in $\mathrm{Hu}$ striatum. One possibility is that processes of $\mathrm{AD}$ are equally toxic to all synapse types in cerebral cortex, and that all subtypes are lost proportionately, and therefore transparent to our end point of percentage + particles. Our data comparing striatum with MFG suggest another possibility, loss of trophism in AD cerebral cortex. In striatum, percerntage particles $+\mathrm{A} \beta_{42}$ was strongly positively correlated with several synaptic markers, but in MFG there was no correlation. A mechanistic basis for this apparent trophic activity associated with $A \beta_{42}$ in striatum but not MFG is unclear, but perhaps is related to the spread of pathological tau to the cerebral cortex but not striatum in AD. It is interesting to speculate that lack or blockade of a trophic effect associated with processes that lead to increased synaptic $A \beta_{42}$ in MFG, rather than direct neurotoxicity, may lead to broad proportionate loss of cerebral cortical synapses in AD.

Our results add novel observations to the synaptic accumulation of $A \beta_{42}$ and PHF-tau in AD and LBD. Others have reported that $A \beta$ peptides preferentially accumulate in + VGLUT1 synaptosomes from cerebral cortex in $\mathrm{AD} .{ }^{13}$ We observed that $A \beta_{42}$ dual labeled a low percentage of all six particle subtypes in MFG and all striatal regions from the Control-Low Path group. The percentage particles dual labeled for $A \beta_{42}$ increased significantly in $A D$ for three synaptic markers (VGLUT1, VGLUT2, and VGAT) in MFG and striatal regions; the increase in dual-labeled particles was greater for VGLUT1 and VGLUT2 than VGAT. Increase in dual-labeled $+\mathrm{A} \beta_{42}$ particles was less robust in LBD and significant only for excitatory particles. These data suggest that $A \beta_{42}$ accumulated preferentially in excitatory synapses in $\mathrm{AD}$ and DLB, and also inhibitory synapses in AD. Finally, considering the possible overlap in the pathogenesis of $\mathrm{AD}$ and $\mathrm{LBD},+\mathrm{DAT} /+\mathrm{A} \beta_{42}$ particles did not increase in $\mathrm{AD}$ or LBD group, suggesting that dopaminergic degeneration in both diseases is $A \beta_{42}$ independent. 
Unlike $A \beta_{42}$, PHF-tau was detected only in MFG in AD and LBD, but not in any region of striatum. The percentage + PHF-tau particles in MFG trended to higher values in all groups with high $\mathrm{AD}$ pathological changes, but this was only significant for Control-Low Path versus AD dementia $(P<0.05)$. Like $\mathrm{A} \beta_{42}$, the percentage + PHF-tau particles was not correlated with any of the synaptic markers in MFG. Data from animal models suggest some sort of cooperativity between $\mathrm{A} \beta_{42}$ and PHF-tau. ${ }^{39}$ Our data are consistent with these proposals in MFG but not in striatum. Indeed, MFG synaptic particles colabeled with $A \beta_{42}$ and PHF-tau were more robustly correlated with clinical expression than were +PHF-tau alone (Figure 4), and percentage particles $+\mathrm{A} \beta_{42}$ correlated positively with + PHF-tau in MFG (Figure 5). This was not the case in the striatum, where there was at least as abundant percentage particles $+\mathrm{A} \beta_{42}$ as in MFG but PHF-tau was lower than the limit of detection. How cooperativity between synaptic $\mathrm{A} \beta_{42}$ and PHF-tau might take place in MFG but not striatum cannot be determined from our observational data but may involve transynaptic routes of transmission from the medial temporal lobe. ${ }^{40}$

In summary, we have demonstrated the fidelity of synaptosome preparations from Hu rapid brain autopsy by close comparison with NHP brain prepared under optimal experimental conditions, and observed two types of selective synaptic degeneration in Hu striatum: dopaminergic degeneration with LBD and regional serotonergic degeneration with inheritance of APOE $\varepsilon 4$; the former was previously validated in a toxic $\mathrm{Mu}$ model,${ }^{15}$ and the latter was validated herein in a TR APOE Mu model. Expanding on the results of others, we did not observe selective synaptic degeneration in MFG with AD dementia, AD neuropathologic features, synaptic $A \beta_{42}$, or synaptic PHF-tau. By comparing MFG with striatum, our results are consistent with lost apparent trophic effect associated with increasing synaptic $A \beta_{42}$ with $A D$ in MFG. Although speculative, lost $\mathrm{A} \beta_{42}$-associated trophism, perhaps related to cooperative action with PFH-tau, in cerebral cortex might explain our inability to detect selective synaptic degeneration in MFG in contrast to striatum.

\section{Acknowledgment}

We thank Dr. Nobuyo Maeda (The University of North Carolina, Chapel Hill, NC) for mice homozygous for targeted replacement of the mouse $a p o E$ gene with exon 1 of human $A P O E \varepsilon 3$ or APOE $\varepsilon 4$, backcrossed onto a C57BL/6 genetic background.

\section{References}

1. Nelson PT, Alafuzoff I, Bigio EH, Bouras C, Braak H, Cairns NJ, et al: Correlation of Alzheimer disease neuropathologic changes with cognitive status: a review of the literature. J Neuropathol Exp Neurol 2012, 71:362-381
2. Braak H, Thal DR, Ghebremedhin E, Del Tredici K: Stages of the pathologic process in Alzheimer disease: age categories from 1 to 100 years. J Neuropathol Exp Neurol 2011, 70:960-969

3. Cholerton B, Larson EB, Quinn JF, Zabetian CP, Mata IF, Keene CD, Flanagan M, Crane PK, Grabowski TJ, Montine KS, Montine TJ: Precision medicine: clarity for the complexity of dementia. Am J Pathol 2016, 186:500-506

4. Halliday GM, Leverenz JB, Schneider JS, Adler CH: The neurobiological basis of cognitive impairment in Parkinson's disease. Mov Disord 2014, 29:634-650

5. Hansen LA, Daniel SE, Wilcock GK, Love S: Frontal cortical synaptophysin in Lewy body diseases: relation to Alzheimer's disease and dementia. J Neurol Neurosurg Psychiatry 1998, 64:653-656

6. Shim KS, Lubec G: Drebrin, a dendritic spine protein, is manifold decreased in brains of patients with Alzheimer's disease and Down syndrome. Neurosci Lett 2002, 324:209-212

7. Sze CI, Bi H, Kleinschmidt-DeMasters BK, Filley CM, Martin LJ: Selective regional loss of exocytotic presynaptic vesicle proteins in Alzheimer's disease brains. J Neurol Sci 2000, 175:81-90

8. Zaja-Milatovic S, Keene CD, Montine KS, Leverenz JB, Tsuang D, Montine TJ: Selective dendritic degeneration of medium spiny neurons in dementia with Lewy bodies. Neurology 2006, 66:1591-1593

9. Zaja-Milatovic S, Milatovic D, Schantz AM, Zhang J, Montine KS, Samii A, Deutch AY, Montine TJ: Dendritic degeneration in neostriatal medium spiny neurons in Parkinson disease. Neurology 2005, 64:545-547

10. Bilousova T, Miller CA, Poon WW, Vinters HV, Corrada M, Kawas C, Hayden EY, Teplow DB, Glabe C, Albay R 3rd, Cole GM, Teng E, Gylys KH: Synaptic amyloid-beta oligomers precede p-tau and differentiate high pathology control cases. Am J Pathol 2016, 186 : $185-198$

11. Sokolow S, Henkins KM, Bilousova T, Gonzalez B, Vinters HV, Miller CA, Cornwell L, Poon WW, Gylys KH: Pre-synaptic C-terminal truncated tau is released from cortical synapses in Alzheimer's disease. J Neurochem 2015, 133:368-379

12. Sokolow S, Henkins KM, Williams IA, Vinters HV, Schmid I, Cole GM, Gylys KH: Isolation of synaptic terminals from Alzheimer's disease cortex. Cytometry A 2012, 81:248-254

13. Sokolow S, Henkins KM, Bilousova T, Miller CA, Vinters HV, Poon W, Cole GM, Gylys KH: AD synapses contain abundant Abeta monomer and multiple soluble oligomers, including a $56-\mathrm{kDa}$ assembly. Neurobiol Aging 2012, 33:1545-1555

14. Gylys KH, Fein JA, Cole GM: Quantitative characterization of crude synaptosomal fraction (P-2) components by flow cytometry. J Neurosci Res 2000, 61:186-192

15. Postupna NO, Keene CD, Latimer C, Sherfield EE, Van Gelder RD, Ojemann JG, Montine TJ, Darvas M: Flow cytometry analysis of synaptosomes from post-mortem human brain reveals changes specific to Lewy body and Alzheimer's disease. Lab Invest 2014, 94: $1161-1172$

16. Ventura-Antunes L, Mota B, Herculano-Houzel S: Different scaling of white matter volume, cortical connectivity, and gyrification across rodent and primate brains. Front Neuroanat 2013, 7:3

17. Heuer E, Rosen RF, Cintron A, Walker LC: Nonhuman primate models of Alzheimer-like cerebral proteopathy. Curr Pharm Des 2012 18:1159-1169

18. Xu PT, Schmechel D, Rothrock-Christian T, Burkhart DS, Qiu HL, Popko B, Sullivan P, Maeda N, Saunders AM, Roses AD, Gilbert JR: Human apolipoprotein E2, E3, and E4 isoform-specific transgenic mice: human-like pattern of glial and neuronal immunoreactivity in central nervous system not observed in wild-type mice. Neurobiol Dis 1996, 3:229-245

19. Montine TJ, Sonnen JA, Montine KS, Crane PK, Larson EB: Adult changes in thought study: dementia is an individually varying convergent syndrome with prevalent clinically silent diseases that may be modified by some commonly used therapeutics. Curr Alzheimer Res 2012, 9:718-723 
20. Cholerton B, Larson EB, Baker LD, Craft S, Crane PK, Millard SP, Sonnen JA, Montine TJ: Neuropathologic correlates of cognition in a population-based sample. J Alzheimers Dis 2013, 36:699-709

21. American Psychiatric Association: Diagnostic and Statistical Manual of Mental Disorders, ed 4. Washington, DC: American Psychiatric Association, 1994

22. McKhann G, Drachman D, Folstein M, Katzman R, Price D, Stadlan EM: Clinical diagnosis of Alzheimer's disease: report of the NINCDS-ADRDA Work Group under the auspices of Department of Health and Human Services Task Force on Alzheimer's Disease. Neurology 1984, 34:939-944

23. Hyman BT, Phelps CH, Beach TG, Bigio EH, Cairns NJ, Carrillo MC, Dickson DW, Duyckaerts C, Frosch MP, Masliah E, Mirra SS, Nelson PT, Schneider JA, Thal DR, Thies B, Trojanowski JQ, Vinters HV, Montine TJ: National Institute on Aging-Alzheimer's Association guidelines for the neuropathologic assessment of Alzheimer's disease. Alzheimers Dement 2012, 8:1-13

24. Montine TJ, Phelps CH, Beach TG, Bigio EH, Cairns NJ, Dickson DW, Duyckaerts C, Frosch MP, Masliah E, Mirra SS, Nelson PT, Schneider JA, Thal DR, Trojanowski JQ, Vinters HV, Hyman BT: National Institute on Aging-Alzheimer's Association guidelines for the neuropathologic assessment of Alzheimer's disease: a practical approach. Acta Neuropathol 2012, 123:1-11

25. Cudaback E, Li X, Montine KS, Montine TJ, Keene CD: Apolipoprotein E isoform-dependent microglia migration. FASEB J 2011, 25: 2082-2091

26. Cudaback E, Li X, Yang Y, Yoo T, Montine KS, Craft S, Montine TJ, Keene CD: Apolipoprotein C-I is an APOE genotype-dependent suppressor of glial activation. J Neuroinflammation 2012, 9:192

27. Yang Y, Keene CD, Peskind ER, Galasko DR, Hu SC, Cudaback E, Wilson AM, Li G, Yu CE, Montine KS, Zhang J, Baird GS, Hyman BT, Montine TJ: Cerebrospinal fluid particles in Alzheimer disease and Parkinson disease. J Neuropathol Exp Neurol 2015, 74: 672-687

28. Maezawa I, Maeda N, Montine TJ, Montine KS: Apolipoprotein E-specific innate immune response in astrocytes from targeted replacement mice. J Neuroinflammation 2006, 3:10

29. Maezawa I, Nivison M, Montine KS, Maeda N, Montine TJ: Neurotoxicity from innate immune response is greatest with targeted replacement of E4 allele of apolipoprotein E gene and is mediated by microglial p38MAPK. FASEB J 2006, 20:797-799

30. Maezawa I, Zaja-Milatovic S, Milatovic D, Stephen C, Sokal I, Maeda N, Montine TJ, Montine KS: Apolipoprotein E isoformdependent dendritic recovery of hippocampal neurons following activation of innate immunity. J Neuroinflammation 2006, 3:21
31. Li X, Montine KS, Keene CD, Montine TJ: Different mechanisms of apolipoprotein E isoform-dependent modulation of prostaglandin E2 production and triggering receptor expressed on myeloid cells 2 (TREM2) expression after innate immune activation of microglia. FASEB J 2015, 29:1754-1762

32. Lemere CA, Beierschmitt A, Iglesias M, Spooner ET, Bloom JK, Leverone JF, Zheng JB, Seabrook TJ, Louard D, Li D, Selkoe DJ, Palmour RM, Ervin FR: Alzheimer's disease abeta vaccine reduces central nervous system abeta levels in a non-human primate, the Caribbean vervet. Am J Pathol 2004, 165:283-297

33. Sonnen JA, Santa Cruz K, Hemmy LS, Woltjer R, Leverenz JB, Montine KS, Jack CR, Kaye J, Lim K, Larson EB, White L, Montine TJ: Ecology of the aging human brain. Arch Neurol 2011, 68 : $1049-1056$

34. Morgan DG, May PC, Finch CE: Dopamine and serotonin systems in human and rodent brain: effects of age and neurodegenerative disease. J Am Geriatr Soc 1987, 35:334-345

35. Guerreiro R, Escott-Price V, Darwent L, Parkkinen L, Ansorge O, Hernandez DG, et al: Genome-wide analysis of genetic correlation in dementia with Lewy bodies, Parkinson's and Alzheimer's diseases. Neurobiol Aging 2016, 38:214.e7-214.e10

36. Mata IF, Leverenz JB, Weintraub D, Trojanowski JQ, Hurtig HI, Van Deerlin VM, Ritz B, Rausch R, Rhodes SL, Factor SA, WoodSiverio C, Quinn JF, Chung KA, Peterson AL, Espay AJ, Revilla FJ, Devoto J, Hu SC, Cholerton BA, Wan JY, Montine TJ, Edwards KL, Zabetian CP: APOE, MAPT, and SNCA genes and cognitive performance in Parkinson disease. JAMA Neurol 2014, 71:1405-1412

37. Tsuang D, Leverenz JB, Lopez OL, Hamilton RL, Bennett DA, Schneider JA, Buchman AS, Larson EB, Crane PK, Kaye JA, Kramer P, Woltjer R, Trojanowski JQ, Weintraub D, Chen-Plotkin AS, Irwin DJ, Rick J, Schellenberg GD, Watson GS, Kukull W, Nelson PT, Jicha GA, Neltner JH, Galasko D, Masliah E, Quinn JF, Chung KA, Yearout D, Mata IF, Wan JY, Edwards KL, Montine TJ, Zabetian CP: APOE epsilon4 increases risk for dementia in pure synucleinopathies. JAMA Neurol 2013, 70:223-228

38. Holmes SE, Esterlis I, Mazure CM, Lim YY, Ames D, RaineySmith S, Martins RN, Salvado O, Dore V, Villemagne VL, Rowe CC, Laws SM, Masters CL, Maruff P, Pietrzak RH: beta-Amyloid, APOE and BDNF genotype, and depressive and anxiety symptoms in cognitively normal older women and men. Am J Geriatr Psychiatry 2016, 24:1191-1195

39. Spires-Jones TL, Hyman BT: The intersection of amyloid beta and tau at synapses in Alzheimer's disease. Neuron 2014, 82:756-771

40. Hyman BT: Tau propagation, different tau phenotypes, and prion-like properties of tau. Neuron 2014, 82:1189-1190 